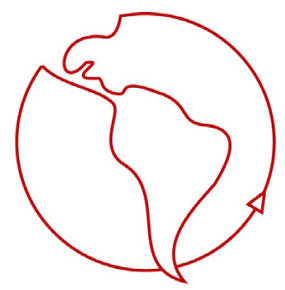

\title{
Nuevas Exclusiones en la Complejidad Social Contemporánea: El Caso Mapuche
}

Dr. Rolf Foerster

Departamento de Antropología Universidad de Chile

rfoerste@uchile.cl

\section{Introducción}

La actual comprensión de la "cuestión mapuche" está regida por tres horizontes conceptuales y normativos (ergo, narrativas) y de cada uno de ellos se desprenden exclusiones e inclusiones.

¿Cuáles son esos horizontes? Dos de ellos emergieron en el siglo XIX en el contexto de la "Pacificación de la Araucanía". La frase de Cornelio Saavedra encargado de ese proceso, al Presidente de la República en 1862, sintetiza claramente en una frase lo que van a ser dos de estos horizontes: "la ocupación nos a costado mucho mosto, mucha música y poca pólvora". Si bien es cierto que la historia heroica, la de la "pólvora", se remontaba al siglo XVI, los hechos del siglo XIX, le otorgaron un nuevo giro al estar ligada ahora -de manera inseparable- al la de las otras dos narrativas (la del "mosto" y la del "pacto").

\section{La Narrativa del Mosto y sus Exclusiones e Inclusiones}

Efectivamente, desde esa fecha hasta el día de hoy, "la música y el mosto" han servido para construir un relato referido a la aculturación progresiva de los mapuches en el marco del Estado y de la nación.

Sergio Villalobos nos dice:

"Desde el siglo XVII los caciques procuraban vestirse y armarse al estilo español, sea por razones de utilidad o de prestigio. No estará de más recordar al cacique Peñoleo, sus mujeres y mocetones, viviendo en ranchos en las afueras de Concepción, vestidos como huincas y borrachos el día entero". ${ }^{1}$

Otra referencia del mismo autor, ahora ligada al contexto de producción de la frase paradigmática:

"Al tomarse la determinación de apoyar con el ejército la integración de la Araucanía, se temió conforme la vigencia del mito [de la guerra], que habría una catástrofe sangrienta de cuyos resultados se dudaba. Tanto es así que en algunos círculos se criticó duramente la decisión.

Llevado el intento adelante a partir del año 1862, resultó que hasta el sector de Angol la resistencia no pasó de las bravatas, la observación de algunos grupos indígenas y unas escaramuzas sin la menor consecuencia. Prevaleció, en cambio, la actitud pasiva y los caciques y sus mocetones se dieron por contentos con la música de la banda militar, que les regalaba con marchas y música de ópera, y el mosto que se les repartía con generosidad".2

\footnotetext{
${ }^{1}$ Reseña al libro de Arturo Leiva (El primer avance a la Araucanía, Angol, 1862), en revista de Historia, N.20, 1985, pág.:519-523, la cita corresponde a la página 521.

${ }^{2}$ En Araucanía. Temas de historia fronteriza, Sergio Villalobos y Jorge Pinto (comps.), ediciones Universidad de la Frontera, Temuco, 1985. pp. 7-30, la cita corresponde a la página 26-27.
} 
Para esta corriente el mestizaje, en el siglo XIX-XX, será una continuación de los siglos anteriores y adquirirá el carácter de "síntesis" en el "roto chileno" (para la izquierda) o en la "raza chilena" (para la derecha). Estas nociones tornarán incomprensible cualquier planteamiento autonómico que pueda emerger de ellas (a no ser que éste fuera impulsado desde fuera, por ejemplo, por los antropólogos).

Esta postura es sustentada desde la derecha (El Mercurio) a la izquierda (Saavedra), pasando por el centro DC (Sergio Villalobos) y su discurso ha sido hegemónico, ${ }^{3}$ o sea, su carácter persuasivo y no coercitivo se ha impuesto sobre los otros dos. Una razón explicativa radica en el predominio del paradigma de la patria (patrimonial-territorial) por sobre el de la nación y la democracia. Es decir, aquel en el que la soberanía es entendida en términos territoriales, ejercida por el Estado, y no como soberanía popular ejercida, en principio, por la nación entera. ${ }^{4}$ Otra razón, complementaria a la anterior es la siguiente: la inclusión de los mapuches en la nación y en el Estado fue -para las elites del siglo XIX y del XX- una tarea moral y un deber patriótico incuestionable. Los mapuches eran la encarnación "terrenal" de la patria y no podían estar "incluidos" como un "estamento" o como "salvajes".

La exclusión máxima que observa esta narrativa, desde mediado el siglo XX, es la pobreza y su instrumento privilegiado, a partir de la década de los 80, la encuesta Casen. Es interesante notar cómo esta lectura ronda asimismo la mente de algunos funcionarios y asesores de la CONADI cuando han debido enfrentar el complejo tema de la demanda mapuche por tierra a través del Fondo de Tierras (que ocupa casi el 75\% de los recursos de la CONADI). Hasta fines de los 90 las preguntas eran: ¿Son demandas propias a todo campesino (letra $\mathbf{A}$ de la ley indígena) o demandas marcadas por la historia (letra $\mathbf{B}$, de la ley indígena)? ¿Cuál es el criterio para entregar tierras: moral (saldar una deuda histórica), político (minimizar las situaciones de conflicto) o productivo (promover la transformación del campesino minifundario mapuche en un próspero agricultor)? Actualmente los asesores parecen inclinarse por este último criterio:

“...las evidencias a la mano nos permiten afirmar que con toda probabilidad la asignación de tierras a grupos de personas y comunidades siguiendo los actuales criterios de asignación sólo contribuye a entregar tierras a poblaciones indigentes, con muy escasa capacitación y experiencia y potencialidad productiva silvo agropecuaria, escasos ahorros y limitaciones para acceso a créditos, en fin, con problemas para gestionar en forma eficiente sus predios recientemente adquiridos. Todo ello pronostica un cambio en la propiedad de la tierra pero no necesariamente una elevación del nivel de vida de los beneficiarios". 5

Planteada así la crítica la respuesta es obvia.

\section{La Narrativa de la Pólvora, su Exclusión e Inclusión por el Etnonacionalismo}

\footnotetext{
${ }^{3}$ Hegemonía: "una condición de la dominación (D), tal que, en la composición orgánica de esta última, la Persuación (P) exceda a la Coerción (C)" (Ranajit Guha).

${ }^{4}$ Reflexiones americanas. Ensayos de intra-historia, LOM, Santiago, 1999, la referencia corresponde a la pág.:216.

5 "Estudio identificación de familias elegibles para el subsidio de aplicación artículo 20 letra a", CERC, 2004, la cita corresponde a la pág.:65.
} 
La segunda narrativa está marcada por la "pólvora" y ha estado siempre presente en un sector de la dirigencia mapuche, sobre todo en los últimos años, pero también emerge en algunos de nuestros relatos históricos -la mentada guerra de 300 años- e incluso en nuestra propia auto comprensión como sociedad. ${ }^{6}$

[Chile fue] “...la única colonia que no logró someter a la más importante de sus etnias originarias, los mapuches, lo cual llevó a una guerra permanente que fortaleció el rol del Estado defensor. Ese orden representado por el Estado y la Iglesia fue pensado como una protección frente a la amenaza de desorden... Orden y temor forman, muy tempranamente, el contexto que dio sentido a las relaciones de poder" (PNUD, 2004:73).

Sin embargo, más adelante el Informe del PNUD argumenta lo contrario, el indígena ya no representa un peligro, pero su sumisión es una amenaza para el cambio:

"La formación histórica del carácter. El origen histórico de Chile sería el autoritarismo del conquistador y la sumisión de los indígenas" (PNUD, 2004:105).

Las figuras estelares de la historia heroica son Lautaro para la colonia, Mangil y Quilapán para el siglo XIX y, para fines del siglo XX, Alex Lemún.

A diferencia de la narrativa anterior el proceso de aculturación y de mestizaje pareciera no existir, los mapuches habrían podido preservar su cultura y su identidad en sus espacios territoriales del Walmapu. No se trata de una exageración. Veamos dos variantes. Una de ellas es desarrollada por José Bengoa y la otra por el Consejo de Todas las Tierras.

Bengoa, en su texto ya clásico de 1985:

"La sociedad mapuche de la primera mitad del siglo XIX fue muy flexible ante la influencia externa, justamente por poseer una libertad territorial y política completa... Cuando existe independencia política total, una sociedad puede exponerse abiertamente al cambio cultural. No teme desaparecer. Cuando, en cambio, una sociedad está sometida, depende política, territorial, económicamente de otra que la oprime; se transforma en una sociedad conservadora, cierra filas en torno a su cultura tradicional y se aferra a ella con todas sus fuerzas. Es lo que sucedió a los mapuches con la derrota de fines de siglo".

Pasemos al Consejo. En su proyecto de ley formulado en 1991, expresa:

"En la presente ley se reconoce el derecho a la educación mapuche a partir de su propia filosofía, historia y sabiduría controlada y dirigida por los propios mapuches, ejerciendo de este modo el derecho a la autodeterminación de la nación... La nación mapuche tiene el derecho a desarrollar y controlar su sistema educacional propio en su cultura, ciencia y sabiduría, para ello usará el principio de territorialidad y la participación de sus miembros por lo que a través de la presente ley se propone la creación de la Escuela Mapuche". ${ }^{8}$

\footnotetext{
${ }^{6}$ Véase por ejemplo el último informe de PNUD donde el tema del conflicto con los mapuches habría marcado nuestro ethos.

${ }^{7}$ Historia del pueblo mapuche, siglo XIX y XX, SUR, Santiago, 1985, la cita corresponde la pág.:155.

${ }^{8}$ En Voz Mapuche Aukiñ, $\mathrm{N}^{\circ} 4$, Art. "Proyecto de Ley de nuestras autoridades originarias" (febrero de 1991). Lamentablemente no tenemos los $\mathrm{N}^{\circ} 2$ y 3 donde están las otras partes de este proyecto de ley.
} 
Así, el mundo mapuche habría estado mudo, pero ahora comienza a hablar, por supuesto a través del Consejo:

"Nosotros autoridades Originarias Mapuche, Lonko (jefe político de cada comunidad), Machi (encargada de la medicina, educación y filosofía), Weupife (historiador y relator de nuestra memoria histórica milenaria), Ngenpin (jefe político religioso del territorio mapuche), Werken (mensajero del pensamiento de las comunidades). Nos hemos reconstituido después de 109 años, fecha en que nuestro pueblo perdiera el control de nuestro territorio y su independencia política como pueblo, siendo este el resultado directo de la invasión de parte del Ejército en nombre del Estado-nación de Chile, hecho que se conoce en la historia como Pacificación de la Araucanía (1881), desde entonces nuestras autoridades de las respectivas comunidades les arrancaron y desconocieron su poder, relegándolos en nuestro propio territorio, subordinándonos estructural e ideológicamente en cuanto a la forma de organización y concepción de la vida. Considerando la innegable existencia como pueblo y sus autoridades, nos hemos convocado en la Primera Conferencia Nacional realizada los días 23 al 26 de abril de 1990, luego que permaneciéramos en silencio por más de un siglo". 9

No todos los intelectuales mapuches están de acuerdo con esta mirada. El más crítico ha sido José Marimán:

"no hay una historia mapuche en el sentido lineal, con estructuras que se preservan en el tiempo; sino varias". Así "Este tipo de alusiones al pasado, son las que me llevan a afirmar que se trata de reconstrucciones míticas, y en consecuencia equivocadas. El fundamentalismo de $\mathrm{AWNg}^{10}$ [Consejo] no es una defensa de lo verdadero, sino una idea del pasado que se construye sobre el pasado en el discurso de sus dirigentes. Al hacerme responsable de esta opinión, lo hago consciente que del pasado sólo hay lecturas hechas por los historiadores. Lecturas que serán más/menos creíbles dependiendo de la rigurosidad del método con que se logran esas imágenes. En el caso de AWNg esta visto que no existe esa rigurosidad, sino más bien, una manipulación flagrante del pasado". ${ }^{11}$

Más ello no significa que Marimán se oponga al proyecto del Consejo en lo que se refiere a la tarea etnonacionalista. Sus diferencias deben ubicarse en el plano de la comprensión del pasado-presente y en la valoración de las "estructuras" tradicionales de poder (machis, lonkos, etc.). Este es quizás uno de los debates más interesantes que ha desarrollado la intelectualidad mapuche (presente últimamente en el diario Azkintuwe) y que tiene también su correlato en el espacio literario, por ejemplo entre la poesía de Elicura Chihuailaf y de Jaime Huenún.

El tema de la exclusión que surge en esta narrativa ya no es la del mapuche pobre, sino el de la nación mapuche. De allí que la tarea prioritaria, para estas organizaciones, ha sido potenciar este proyecto (de la etnia a la nación). Pienso que el extremo de esta posición es la elaborada por la Coordinadora Arauco Malleco, la cual por primera vez niega toda posibilidad de pacto con el Estado, al transformarlo en su principal enemigo.

\section{La Tercera Narrativa: La del Pacto, su Exclusión e Inclusión}

\footnotetext{
${ }^{9}$ Carta al Presidente de la República, 10 de abril de 1991, en Voz Mapuche Aukiñ, º6 (abril de 1991).

${ }^{10}$ Aukiñ Wallmapu Ngulam.

${ }^{11}$ La Organización mapuche Aukiñ Wallmapu Ngulam.
} 
Por último existe, como dijimos, una tercera narrativa, difícil de reconstruir pues ha sido invisibilizada por las anteriores. Vamos a denominarla como la del "pacto". Esta narrativa hunde sus raíces en el siglo XVII, se despliega a lo largo del siglo XVIII a través del "pacto colonial", reaparece en el siglo XIX como "pacto republicano" (su mejor expresión es la ley de 1866 que da origen al sistema reduccional) y, en el XX como "pacto democrático" cuyas expresiones han sido: en la década de 1950, el acuerdo de la Corporación Araucana con el gobierno de Ibáñez (creación de la DASIN) y a fines del 80, con el acuerdo de Nueva Imperial (creación en 1993 de la CONADI).

La idea central del pacto es la del "tercer incluido". En el pacto colonial, éste era una suerte de autoridad compuesta por el representante del Rey -el Gobernador- y los caciques gobernadores, los cuales acordaban, en los "parlamentos" los vínculos o nexos entre las "dos repúblicas". Esos acuerdos, según Alamiro de Ávila, uno de los más destacados historiadores del derecho en Chile, eran "verdaderos tratados internacionales". Téngase presente que gracias a esos acuerdos el Bío Bío se mantuvo como la frontera entre ambas "naciones".

Una aproximación a los pactos bajo la república, obliga a una lectura de lo sancionado en los parlamentos en Tapihue (1825), en Arauco (1837), en Tucapel (diciembre de 1846; marzo de 1860 y diciembre de 1861), en Santiago (abril de 1862), en Levu (octubre de 1862), en Angol, en Hipinco (noviembre de 1869) y en Toltén (enero de 1870). De ellos, el de más larga duración fue la alianza del gobierno con los caciques abajinos (Mariluan, Painemal, Coñuepan) y se remonta a la década de 1820, con la "Guerra a muerte". Sin embargo, pensamos que la intencionalidad de los pactos por parte del gobierno, desde fines de 1859 , apuntan a un sentido diferente, ya no al "colonial" sino al "republicano" (sería interesante ver y contrastar los pactos de la autoridad de Concepción -José María de la Cruz de por medio- con los "arribanos" antes del 59).

El "pacto republicano" exige la subordinación de todas los personas y estamentos al Estado, en un tipo de vínculo que supone para los mapuches la pérdida de la soberanía política (militar) y territorial (es el pacto de subordinación o de sumisión). ${ }^{12}$ El Estado es ahora el "tercer incluido". Lo que se gana con ese pacto es un nuevo estatus para las personas: el de ciudadano, que supone la garantía de un trato igual frente a la ley. La pregunta que nos hacemos es si los mapuches interpretaron el "pacto" bajo esas coordenadas o lo hicieron bajo las del antiguo "pacto colonial". Nuestra interpretación sobre el pacto republicano, es que tanto la parte chilena como la mapuche establecieron un pacto híbrido, que permitió entre otras cosas los títulos de merced así como la permanencia de las autoridades tradicionales (que hacen del Presidente su último interlocutor). Será ese pacto híbrido el que gatillará las movilizaciones mapuches en el siglo XX.

Las movilizaciones masivas mapuches comenzaron en la década de 1950, primeramente en los tribunales; después, en los 60-70 con las "corridas de cerco" y "tomas de fundo". La razón de éstas parece ser simple: el pacto del siglo XIX había entrado en crisis porque su mejor expresión, el sistema reduccional, ya no

\footnotetext{
${ }^{12}$ En el parlamento de Tapihue, enero de 1825, se acordó, entre otras cosas:

"1. Convencidos ambos jefes de las grandes ventajas de hacernos una sola familia, ya para oponernos a enemigos de nuestro país, ya para aumentar y solidar el comercio, y hacer cesar del todo los males que ha afligido a la República en catorce años de consecutiva guerra ha venido D. Francisco Mariluan como autorizado por todos los Caciques en unirse en opinión y derechos a la gran familia chilena".

2. El Estado se compone desde el despoblado de Atacama hasta los últimos límites de la provincia de Chiloé.

3. Todos los que existen entre ambas líneas serán tratados como a ciudadanos chilenos con goce de todas las prerrogativas, gracias y privilegios que les corresponden."
} 
garantizaba la reproducción de esos micro espacios soberanos que eran las comunidades. De allí la necesidad de un nuevo pacto.

En la década de 1950 la Corporación Araucana, después de largas negociaciones con el ibañismo, logró a través de sus diputados -Cayupi y Romero- y del Ministro de Tierras y Colonización -Venancio Coñuepán- la creación de la Dirección de Asuntos Indígenas (DASIN), ${ }^{13}$ institución estatal, dirigida por ellos, que debía velar por el desarrollo de las comunidades y de sus espacios territoriales (de allí su oposición de la ley de división de 1927). En su artículo $3^{\circ}$ se nos dice que la DASIN:

“...tendrá a su cargo la debida organización de las Comunidades Indígenas existentes o que se establezcan en el futuro, la constitución legal de las familias indígenas y de sus derechos patrimoniales. Asimismo tendrá la supervigilancia de la explotación racional de los predios agrícolas del dominio de Comunidades indígenas o de los subdivididos cuyos actuales propietarios indígenas la solicitaren".

En la década de los 60 y en los tres años del Gobierno Popular, la dirigencia mapuche -tanto local-regional como la política- se ligó a las luchas obreras y campesinas en vistas a participar en la Reforma Agraria. Esta alianza les permitió no sólo recuperar la totalidad de sus espacios reduccionales sino también ampliarlos considerablemente (en la provincia de Arauco se superó lo entregado bajo la modalidad reduccional).

La represión, el posterior desmantelamiento del "Estado de compromiso" (nacional popular, corporativo, clientelista) y la emergencia de un Estado liberal, que se aboca a modernizar en el marco de la globalización, generó una doble disyunción o disociación entre Estado y nación y entre representividad y legitimidad (para ocupar los términos de Castells). ${ }^{14}$ Este es el contexto dentro del cual se dibuja el "etnonacionalismo", pero también el nuevo pacto, el de Imperial (1989).

El "nuevo pacto" se presenta en estrecha relación con el de la década del 50, más aún es su mejor expresión al dar continuidad al "tercer incluido". Leamos sólo el primer párrafo de la ley indígena:

"Es deber de la sociedad en general y del Estado en particular, a través de sus instituciones respetar, proteger y promover el desarrollo de los indígenas, sus culturas, familias y comunidades, adoptando las medidas adecuadas para tales fines y proteger las tierras indígenas, velar por su adecuada explotación, por su equilibrio ecológico y propender a su ampliación”.

Pero tengámoslo claro: se trata de un tercer incluido que debe contener, en su interior, a la "dirigencia mapuche", de allí la presencia de los "consejeros indígenas" en el Consejo de la CONADI.

Este "nuevo" pacto incorpora una conciencia de exclusión-inclusión que hace explícito el tema del reconocimiento de los mapuches como grupo. El punto que se abre ahora es: ese grupo es ¿una etnia o una nación? El actual debate tiene como centro la forma de responder a esa pregunta, pues de ello dependerá el modo de encarar la dialéctica inclusión-exclusión y sus consecuencias.

\section{En síntesis}

\footnotetext{
${ }^{13}$ Decreto de fuerza de ley de 25 de Abril de 1953.

${ }^{14}$ Globalización, desarrollo y democracia: Chile en el contexto mundial, FCE, Santiago, 2005.
} 
Tenemos tres opciones:

1) Aquella que reduce la problemática mapuche a la de los pobres, o sea en términos económicos y ciudadanos. La óptica de la inclusión/exclusión es simple: se trata de superar las exclusiones a través de una mejor inclusión.

2) La que observa desde un horizonte etno-nacionalista y que busca en el futuro su propio Estado. Se trata aquí de generar un movimiento "nacionalista" que vaya en contra de las políticas de inclusión del Estado nacional chileno. Su mejor expresión fue/es la Coordinadora Arauco Malleco en su praxis política de potenciar las micro soberanías locales (reduccionales). La lucha contra el "tercer incluido" quedó también de manifiesto cuando el Consejo de Todas las Tierra, citó al Presidente Aylwin a un juicio político que llevaban adelante los lonkos en Temuco.

3) Aquella que trabaja bajo la vieja tradición del pacto, del tercer incluido. Como ya lo señalamos, aquí el debate radica en qué términos debe darse la inclusión, ¿como etnia o como nación? En este argumento el horizonte no está tanto en el "etnonacionalismo" sino más bien en el "multiculturalismo".

\section{Bibliografía}

Castells, Manuel. 2005. Globalización, desarrollo y democracia: Chile en el contexto mundial. Santiago: FCE.

Bengoa, José. 1985. Historia del Pueblo Mapuche, siglo XIX y XX. Santiago: SUR.

García de la Huerta, Marcos. 1999. Reflexiones Americanas. Ensayos de intra-historia. Santiago: LOM.

Villalobos, Sergio y Jorge Pinto (comps.). 1985. Araucanía. Temas de historia fronteriza. Temuco: Ediciones Universidad de la Frontera. 